\title{
"O WORTHY FOOL: MOTLEY IS THE ONLY WEAR": OS ATORES CÔMICOS DO PALCO SHAKESPEARIANO
}

\section{ERIKA DE FREITAS COACHMAN*}

Universidade Federal do Rio de Janeiro (UFRJ), Colégio de Aplicação (CAp), Rio de Janeiro, RJ, Brasil.

Recebido em: 16 set. 2019. Aprovado em: 26 fev. 2021.

Como citar este artigo: COACHMAN, E. de F. "O worthy fool: motley is the only wear": os atores cômicos do palco shakespeariano. Cadernos de Pós-Graduação em Letras, v. 21, n. 1, p. 184-196, jan./abr. 2021. doi: 10.5935/cadernosletras.v21n1p184-196

\section{Resumo}

Nos primeiros anos da carreira de Shakespeare, não era a fama do bardo que atraía multidões para o teatro, mas sim a de seus atores cômicos. Este estudo debruça-se sobre as características de dois deles: Will Kemp e Robert Armin, analisando alguns dos principais aspectos de suas performances cômicas.

\section{Palavras-chave}

Clown. Shakespeare. Ator cômico.

* E-mail: erikacoachman@hotmail.com

(D) https://orcid.org/0000-0001-5805-2864 


\section{INTRODUÇÃO}

"Your words and your performances are no kin together"

(Othello, 4.2.184).

As personagens shakespearianas não podem ser estudadas como as personagens das páginas de um romance literário; como nos alerta Andrew Hartley (2009, p. 158), é fundamental admitir que o texto dramático a que temos acesso hoje é uma tentativa de reconstituição de um espetáculo em que cada personagem dramática era representada por um ator específico da companhia teatral - um ator cujos principais talentos e habilidades eram levados em conta no momento em que Shakespeare criava as dramatis personae de suas obras. Nas palavras de Hartley (2009, p. 159):

Mesmo na página, a personagem em Shakespeare é dramática, ou seja, é parcial e sempre demanda que, pelo menos, se imagine uma presença teatral. Рara mim, portanto, personagem é um produto híbrido do ator e do papel do roteiro, algo que não pertence simplesmente ao documento material e requer as condições materiais do palco para ganhar vida. Sem o corpo do ator, a personagem só existe em potencial $[\ldots]^{1}$.

No palco shakespeariano, uma das principais contribuições do corpo do ator para a construção de sua personagem era a reputação que já tinha construído no decorrer de sua carreira, por ocasião de outras performances, e a familiaridade que o público já tinha com ele (HARTLEY, 2009, p. 159). Era o caso do famoso clown Richard Tarlton (1530-1588), cuja prática influenciou fortemente tanto Will Kemp (1560-1603) quanto Robert Armin (1563-1615), os grandes atores cômicos da companhia de Shakespeare.

Segundo Wiles (1987, p. 61), o termo clown é uma invenção da era elisabetana: a palavra foi criada para designar um rústico ${ }^{2}$ que, por conta de sua

1 "Even on the page, character in Shakespeare is dramatic, which is to say that it is partial and always demands at the very least the imagining of a theatrical presence. Character for me, therefore, is the hybrid production of actor and scripted role, something that cannot inhere merely in the material document and requires the equally material conditions of the stage in order to come into being. Without the actor's body, character only exists in potential [...]."

2 O clown nasceu em Londres, como uma resposta à chegada de imigrantes vindos do interior. Nos anos 1580, Londres era cerca de quinze vezes maior do que qualquer outra cidade inglesa - e não parava de crescer. Segundo Wiles (1987, p. 23), o clown Dick Tarlton ajudou a forjar um senso de comunidade, 
rudeza e ingenuidade, era visto como alguém inferior e ridículo. A origem do termo e sua associação à figura do ator cômico nos remetem inexoravelmente a Tarlton, cujas performances nasciam da fusão dos papéis de rústico e comediante - uma mescla que se consolidou de tal modo no período elisabetano-jaimesco que o termo se tornou polissêmico, podendo designar um rústico, um ator cômico ou, ainda, uma personagem engraçada (WILES, 1987, p. 12).

O improviso era um dos pontos fortes do clowning de Tarlton, em especial no final da peça, quando os espectadores o desafiavam com rimas espertas para tentar derrotá-lo em uma engraçada e competitiva batalha de argúcia (em inglês, battle of wits). Tarlton também sobressaía no canto, como seu sucessor Robert Armin, e duas de suas baladas sobrevivem até os dias de hoje. Não se sabe, no entanto, se Tarlton era um hábil dançarino - ao que tudo indica, foi Will Kemp que, logo depois, transformou a dança em um dos principais elementos da performance cômica do palco shakespeariano (WILES, 1987, p. 14-15).

Nos tempos de Shakespeare, não havia uma distinção clara entre o clown e o bobo. O próprio texto dramático corrobora essa hipótese, pois apenas uma rubrica se refere à figura do bobo explicitamente, no caso específico do bobo do rei Lear. As demais menções a personagens cômicas usam o termo clown indistintamente (WILES, 1987, p. 69). Apesar de a terminologia permanecer a mesma, é impossível deixar de notar algumas mudanças importantes no clowning do palco shakespeariano. Um claro divisor de águas nesse processo foi a saída inexplicada do célebre clown Will Kemp e o ingresso de Robert Armin na companhia Lord Chamberlain's Men (BELL, 2011, p. 12) - atores cômicos que analisaremos a seguir.

\section{WILL KEMP}

"From the crown of his head to the sole of his food he is all mirth" (Much ado about nothing, 3.2.7-8).

A jest-monger na tradição do saudoso Dick Tarlton, segundo Thomas Nashe, Will Kemp era um ator cômico que não se submetia à tirania do roteiro (WEIMANN; BRUSTER, 2009, p. 85). Antes de se unir à companhia de

pois suas performances eram apreciadas em diferentes estratos sociais, "tanto na corte quanto na taverna" ("both at court and in the tavern"). 
Shakespeare, Kemp ocupava-se de sua carreira solo ou de espetáculos com pequenos grupos de músicos e acrobatas, tanto na Inglaterra quanto em países do continente europeu, como Holanda e Dinamarca. O ponto alto de sua performance era seu talento como dançarino vigoroso, comprovado em diversas ocasiões, como na maratona musical conhecida como Kemp's Nine Daies Wonder, que ele empreendeu ao dançar de Londres até Norwich (WELSFORD, 1935, p. 284; HORNBACK, 2009, p. 132). Seu ingresso na Lord Chamberlain's Men era resultado de um processo mais amplo, da transição de uma longa tradição de mecenato para a emergência do teatro comercial (WEIMANN; BRUSTER, 2009, p. 85). É bem provável que Kemp tenha se unido à companhia londrina na década de $1590^{3}$ por perceber que estar a serviço de um mecenas não era mais o melhor caminho para prosperidade (WILES, 1987, p. 35); e foi justamente esse contexto histórico que propiciou a união do maior dramaturgo e do mais talentoso comediante de seu tempo.

O humor de Kemp já tinha contornos bem delineados antes de seu ingresso na companhia teatral de Shakespeare. Ao contrário da prática contemporânea de casting, em que o diretor escolhe os atores de acordo com as características de suas personagens, eram as características e as habilidades dos atores da companhia que serviam de inspiração para que o dramaturgo construísse suas personagens (CAMPBELL, 1971, p. 3). É o que defende também Wiles (1987, p. 42) ao afirmar:

\begin{abstract}
0 dramaturgo elisabetano sabia que seus atores tinham bagagens bastante individuais como performers. Não havia um diretor para impor um estilo unificado de performance sobre o elenco de uma determinada peça. 0 dramaturgo era, portanto, obrigado a escrever de acordo com as exigências de seus atores. Ele podia moldá-los apenas aos poucos. E muitos, como Kemp, se agarravam firmemente aos seus próprios princípios. ${ }^{4}$
\end{abstract}

Ao contrário do que sugere o senso comum, as peças de Shakespeare não eram obras de uma mente solitária: o texto dramático era produto de um

3 De acordo com Hornback (2009, p. 132), Kemp já tinha sua fama reconhecida em Londres antes de se unir à Lord Chamberlain's Men.

$4 \quad$ "The Elizabethan dramatist knew that his actors had quite individual backgrounds as performers. There was no director to impose a unifying performance style upon a given cast for a given play. The dramatist was therefore obliged to write to the requirements of his actors. He could mould them only by slow degrees. And many, like Kemp, clung tenaciously to principles of their own." 
esforço colaborativo e carregava consigo marcas características não apenas do dramaturgo, mas também dos atores para quem os papéis eram concebidos (WILES, 1987, p. 42). Porém, apesar do trabalho cooperativo das companhias teatrais, inclusive da Lord Chamberlain's Men, é pouco provável que o indomável Will Kemp tenha restringido seu clowning aos limites do roteiro.

Uma de suas principais contribuições para o palco shakespeariano foi sua performance dos jigs - apresentações musicais que mantinham parentesco próximo com a dança folclórica conhecida como morris dance - um componente característico do festival da era Tudor, comandado por um Lord of Misrule (WILES, 1987, p. 31; VIDEBAEK, 1996, p. 4). Originalmente, a morris dance tinha o objetivo de celebrar a escolha de um rei do verão ${ }^{5}$ ou de uma dama de maio; ${ }^{6}$ porém, no apagar das luzes do século XVI, o ritual já havia sofrido mudanças e seu líder passou a ser um bobo, responsável por conduzir a dança. Durante a execução da morris dance, o bobo cortejava um homem disfarçado de mulher, que representava uma versão burlesca da rainha de maio ${ }^{7}$ conhecida como a Donzela Marian ${ }^{8,9}$ (WILES, 1987, p. 44).

À semelhança da tradicional morris dance folclórica, o jig do teatro elisabetano-jaimesco colocava em cena uma dança de casais, mas de modo cômico e extremamente sensual. Os puritanos, em particular, se indignavam com a liberdade com que os atores se moviam no palco durante o jig, pois seus gestos obscenos e comportamento impudico tocavam em temas tabus, desafiando a moral e os bons costumes que eles advogavam (WILES, 1987, p. 45). Mas, para o ousado clown Kemp, incomodá-los não era problema: no decorrer do embate ideológico conhecido como Marprelate controversy, entre 1588 e 1589, Kemp apresentou jigs antimartinistas, ${ }^{10}$ em que debochava dos puritanos. Durante a guerra de panfletos que marcou o período, um dos textos distribuídos criticava duramente uma apresentação que levou ao palco do The Theatre uma espécie de may game fazendo troça de Martin $^{11}$ (HORNBACK,

\footnotetext{
5 "Summer King".

6 “May Lady”.

7 "May Queen”.

8 "Maid Marian".

9 Maid Marian também era conhecida como a amada de Robin Hood.

10 O termo "antimartinista" é utilizado aqui para qualificar um conteúdo crítico aos argumentos puritanos propagados durante a guerra dos panfletos.

11 Martin Marprelate era o pseudônimo adotado pelos puritanos na guerra dos panfletos.
} 
2009, p. 132-133). Ao longo da carreira de Kemp, sua reputação se atrelou de tal forma aos jigs que não raramente seu nome era vinculado a composições que não eram de sua autoria (HORNBACK, 2009, p. 133).

Para os críticos literários que buscam nas peças shakespearianas uma unidade textual, pode parecer sensato analisar o jig como uma apresentação à parte, um número musical completamente dissociado do texto dramático. Porém, à medida que tentamos resgatar a unidade da obra shakespeariana como um evento teatral, é inevitável tratar as peças e os jigs como partes indissociáveis de uma mesma experiência (WILES, 1987, p. 56). A anarquia que arrebatava o palco durante os jigs estabelecia um claro contraste com o final feliz das comédias românticas, marcado pela reconciliação da sociedade e pelo restabelecimento da moral e dos valores do patriarcado. Se o desfecho colocava o que há de mais sublime no amor romântico, o jig deslocava nosso olhar para o que há de mais carnal, para a consumação do casamento. Além disso, o foco do jig no adultério subvertia e parodiava os votos matrimonias:

Ainda de outro ponto de vista, podemos dizer que o jig permite à plateia desconstruir o final da peça. As peças são idealistas na sua filosofia: o amor romântico é apresentado como um estado perfeito que os indivíduos podem alcançar, apesar dos obstáculos que eles e o mundo erguem. 0 jig reduz o casamento a um arranjo material (WILES, 1987, p. 56).'2

Mas, como nos lembra Wiles (1987, p. 56), a apresentação de jigs não era restrita ao encerramento de comédias românticas. Depois da encenação de uma tragédia, por exemplo, a experiência espiritual do herói era desconstruída e, de certo modo, satirizada pela materialidade e pela obscenidade do jig liderado pelo clown. Quando analisado sob um prisma sociológico, o jig emerge como um número capaz de garantir certa dose de simetria à experiência teatral, garantindo que ela seria apreciada por toda sociedade, não apenas pelas camadas mais elevadas (WILES, 1987, p. 56).

No entanto, a busca por prestígio e a mudança da Lord Chamberlain's Men para o Globe Theatre na segunda metade dos anos 1590 fizeram com que o jig fosse cada vez mais deixado de lado. Criticado amplamente tanto por

12 "From yet another point of view, we may say that the jig allows the audience to deconstruct the finale of the play. The plays are idealist in their philosophy: romantic love is presented as a perfect state that individuals can attain, despite the obstacles that they and the world erect. The jig reduces marriage to a material arrangement." 
neoclássicos quanto por puritanos, o jig era um número musical ousado, que não contribuía para elevar o status da companhia e, às vezes, ainda causava tumulto entre a multidão de espectadores. É bem provável que o jig tenha sido um tema importante em uma possível desavença entre Kemp e os outros membros da companhia. Segundo Wiles (1987, p. 47-48), Kemp teria percebido que o novo teatro o privaria da liberdade com que ele já estava habituado no Curtain Theatre e teria optado por voltar à carreira solo.

Uma das principais características das personagens representadas por Kemp era seu baixo status social - uma herança dos traços sociais que marcavam o criado astuto das comédias romanas e italianas (VIDEBAEK, 1996, p. 2). Porém, no final dos anos 1590, a tradicional fusão entre clown e rústico começou a ser desafiada; um dos exemplos mais emblemáticos é representado pela figura esférica do Sir John Falstaff - em que o humor, a astúcia e a invencibilidade do clown convivem com o rótulo social de cavaleiro. Mais adiante, a saída de Kemp da companhia assinalaria o início de uma nova fase para o clowning no palco do Globe: ao contrário de seu antecessor, Robert Armin representaria personagens cômicas cuja linguagem e comportamento não o marcavam necessariamente como um homem simples ou rústico. A ideia não era mais manter os clowns circunscritos a um determinado espectro social, mas sim destacar o fato de que qualquer homem, seja qual for seu status, pode ser um bobo (WILES, 1987, p. 100).

Entretanto, durante a permanência de Kemp na Lord Chamberlain's Men, na maior parte das vezes, mantinha-se nítida uma linha divisória que separava personagens aristocráticas e rústicas; protagonistas e clowns; enredo sério e subenredo cômico. No teatro clássico, os servos cômicos eram identificados pelo uso de uma máscara; já no palco elisabetano-jaimesco, era principalmente o discurso em prosa que distinguia os clowns dos protagonistas e das demais personagens. A escolha da prosa como principal veículo discursivo do humor não era aleatória; afinal, a prosa coloquial reforçava a imagem do clown como alguém que improvisa, que se afasta momentaneamente do universo da ficção para dialogar espontaneamente com a plateia (WILES, 1987, p. 100; VIDEBAEK, 1996, p. 4). Essa relação de proximidade e até de cumplicidade também se estabelecia por conta da posição do clown no palco. O uso da prosa era associado a uma posição no palco mais próxima dos espectadores, permitindo que seus apartes soassem como confidências e suas caretas dificilmente passas- 
sem despercebidas aos olhos do público (WILES, 1987, p. 102); afinal, as performances das personagens cômicas não se limitavam apenas às suas escolhas verbais, mas apelavam frequentemente para o não verbal, como indicam algumas rubricas.

A prosa de Kemp, em particular, era assinalada por aspectos dialógicos, uma sintaxe nada rebuscada e marcadores discursivos característicos de um homem simples, um sujeito do povo (WILES, 1987, p. 101). Até os nomes de alguns clowns serviam para reforçar a separação do subenredo cômico do enredo principal - uma tática que Wiles (1987, p. 103) define como naming convention. $\mathrm{Na}$ Verona de Romeu e Julieta, por exemplo, os nomes italianos não se estendem às personagens cômicas: no final do quarto ato, logo após o funeral de Julieta, o palco é invadido por clowns com nomes ingleses, como o criado Peter e os músicos Simon Catling, Hugh Rebeck e James Soundpost.

A separação do enredo era outra característica que distinguiria as personagens de Kemp das de seu sucessor Robert Armin. Essa separação, já sinalizada pelo emprego da prosa, servia para endossar a função mediadora do clown, uma clara herança da tradição do vício dos interlúdios e das moralidades (WELSFORD, 1935, p. 284; WILES, 1987, p. 102), como já visto. Ao contrário de Armin, Kemp não se preocupava em ocultar sua identidade por completo, nem tinha problemas em romper a ilusão cênica para se dirigir diretamente ao público, usando pronomes de segunda pessoa (WILES, 1987, p. 55, 102, 107). Por volta de 1600, é bastante provável que as orientações do príncipe Hamlet para os clowns tenham evocado a imagem de Will Kemp que, famoso pelos improvisos e pelos anárquicos jigs, tinha acabado de deixar a Lord Chamberlain's Men (WILES, 1987, p. vii-viii). ${ }^{13}$

$13 \mathrm{Na}$ falta de evidências concretas, só é possível especular por que ele teria deixado um empreendimento tão promissor (WILES, 1987, p. 36): com o passar dos anos, Shakespeare, Thomas Pope (-1603), Augustine Phillips (-1605) e até o sucessor de Kemp, o clown Robert Armin, conseguiram adquirir brasões (coats of arms), insígnias que atestavam a ascensão deles à classe aristocrática (WILES, 1987, p. 41). Já o célebre Kemp morreu sem conquistar o mesmo status. Talvez Wiles (1987, p. 41) esteja correto ao afirmar que o clown era avesso às pretensões de se tornar um membro da elite londrina, de ingressar nos meios mais exclusivos dessa sociedade. Talvez sua afinidade pela figura do homem simples que representava no palco tenha extrapolado os limites da ficção: uma simplicidade que ele levou para o túmulo e que se encontra claramente refletida em seu epitáfio - "Kempe, a man" (WILES, 1987, p. 41). 


\section{ROBERT ARMIN}

"When we are born we cry that we are come to this great stage of fools"

(Lear, 4.6.178-9).

A distinção entre clowns e fools, comum na crítica shakespeariana de hoje - com o clown associado a um humor mais vulgar e farsesco, e bobo (fool), a um humor mais refinado e a ironias mais sofisticadas -, não era recorrente nos tempos elisabetano-jaimescos, como vimos. Uma breve análise da genealogia e da etimologia das palavras clown e fool pode ser útil na compreensão dos significados desses termos à época de Shakespeare. Segundo Weimann e Bruster (2009, p. 99), um estudo genealógico da palavra fool nos remete às práticas dos rituais folclóricos ingleses - uma tradição festiva anterior às formas teatrais modernas do clown que, de certo modo, foi uma das fontes de influência sobre o processo de construção da prática de clowning de atores como Tarlton, Kemp e até Armin. Também nos remete à figura do bobo da corte, um bobo profissional que já habitava o mundo da corte inglesa desde a Idade Média - e outros países e continentes desde tempos imemoriais, como atesta Beatrice Otto (2001, p. 272-290). Sob o ponto de vista etimológico, a palavra fool seria um termo importado do francês antigo; já a palavra clown designava historicamente um homem rústico, um significado que só foi apropriado pelo teatro no final do século XVI. Embora muitos críticos atuais associem a diferença entre os termos clown e fool à transição da era Kemp para a era Armin, convém lembrar que não é possível demarcar de modo rígido as diferenças entre as performances de ambos. Primeiramente, é necessário considerar que caberia a Armin representar os papéis outrora desempenhados por Kemp, sempre que a companhia optasse por encenar peças antigas. A diferença entre eles decorre menos de questões teóricas ou conceituais: o mais provável é que as características distintivas de cada um se devam, em certa medida, às rápidas mudanças do cenário cultural em que viviam; em particular, à popularização da ideia de que o clown deve se ocupar, necessariamente, de algum ponto importante da peça, em vez de sempre buscar provocar o riso (WEIMANN; BRUSTER, 2009, p. 100).

Pouco a pouco, ao longo dos primeiros anos do século XVII, o jig e o clowning tradicionais foram relegados a teatros com reputação mais plebeia e com menos prestígio, como o Fortune e o Red Bull (WEIMANN; BRUSTER, 
2009, p. 86; HORNBACK, 2009, p. 183). Embora a saída de Kemp não tenha marcado a completa erradicação dos clowns do Globe Theatre, ela assinalou a transição para um tipo de clowning mais disciplinado, mais submisso à tirania do texto; nas palavras de Richard Helgerson (apud WEIMANN; BRUSTER, 2009 , p. 86), esse advento marcou o "triunfo relativo de um teatro do autor". O novo clown da companhia, o escritor de baladas Robert Armin, foi um dos grandes expoentes de uma nova prática humorística capaz de reconciliar o clowning e a disciplina textual - que até então pareciam práticas absolutamente antagônicas (WEIMANN; BRUSTER, 2009, p. 88). Como afirma Preiss (2015, p. 14), os bobos criados para Robert Armin personificam um clown domesticado, mais submisso ao roteiro dramático.

Kemp e Armin não eram diferentes somente no palco. Registros históricos nos revelam que os atores tinham perfis bastante distintos: segundo Wiles (1987, p. 136), Armin fazia parte de um grupo social em franco processo de ascensão social; além de célebre escritor de baladas, ele era um aprendiz de ourives, um mímico e um intelectual londrino - cujas reflexões estavam em perfeita sintonia com o legado folclórico inglês e com o debate renascentista sobre a tolice (folly) e a loucura (madness). Familiarizado com o latim e o italiano, ele publicou Fool upon fool e Quips upon questions sob o pseudônimo de Snuff, o clown do Curtain Theatre (WILES, 1987, p. 137). Quips upon questions, em particular, descreve a prática de clowns, como o mestre Richard Tarlton, com especial atenção à sua arte de improviso (WILES, 1987, p. 138).

Enquanto Kemp destacava-se na condição de clown representante do homem inglês comum, Armin tornou-se autor de uma linguagem e de um estilo humorístico que pareciam escapar às tentativas de classificação social (WILES, 1987, p. 144): em geral, a origem social de seus bobos é mantida em sigilo. O clowning de Kemp tinha como sua principal marca dramatis personae cuja simplicidade e lógica material serviam para se opor aos sentimentos e aos valores sublimes dos heróis, parodiando-os; Armin, por sua vez, tomou um rumo distinto, optando por dar voz e forma a personagens cômicas versáteis, não necessariamente rústicas, não necessariamente aristocráticas (WILES, 1987, p. 159).

Deixando de lado a linguagem do homem rústico, Armin dedicou-se a explorar as possibilidades cômicas de uma sintaxe mais elaborada (WILES, 1987, p. 161). Além disso, ao passo que Kemp parecia preencher e dominar o palco com sua figura corpulenta, Armin preferia não estar só em cena por muito tempo - o que talvez explique Shakespeare não ter escrito longos monó- 
logos escritos para ele (WILES, 1987, p. 161). Afinal, pelo que indicam seus apelidos diminutivos, como Snuff e Pink, a estrutura física de Armin não era a mesma de seu antecessor (WILES, 1987, p. 139); com a saída de Kemp, as danças vigorosas cederam espaço para o canto, um dos grandes talentos de Armin (VIDEBAEK, 1996, p. 4). A escolha cuidadosa das palavras de suas canções nos revela que ele não estava improvisando, mas sim dando sua voz a letras elaboradas. Embora a prosa continue sendo o estilo favorito de suas personagens, não são raros os momentos em que elas interagem em verso. $\mathrm{Na}$ última peça de Shakespeare, A tempestade, as falas de Caliban são predominantemente em verso - algo impensável dentro das convenções que regiam a linguagem do humor de Kemp (WILES, 1987, p. 159; BELL, 2011, p. 129-130).

Ao contrário de seu antecessor, Armin não buscava se consolidar como mediador entre o mundo da peça e o dos espectadores. Nas falas escritas para ele, não é encontrado o pronome de segunda pessoa como forma de estabelecer diálogo com o público: Armin prefere não conversar com os espectadores, mas sim com seu alter ego (WILES, 1987, p. 161). Outra característica recorrente das personagens cômicas de Armin, segundo Wiles (1987, p. 148), era a semelhança com o cão: em Troilus e Créssida, Térsites, o bobo com senso de humor corrosivo, é comparado com um cão pelo menos três vezes $(2.1 .7,78 ; 5.1 .25)$ : o mais provável é que a feiura e a estatura reduzida de Armin sugerissem essa imagem.

\section{O CLOWN SAI DE CENA}

"Our revels are now ended" (The Tempest, 41.148).

No capítulo "License revoked”, Hornback (2009, p. 183) nos conta que Armin foi o último especialista em bobos inteligentes de que se tem notícia. $\mathrm{O}$ ano de 1613, em que ele se aposentou e deixou a companhia, marcou o declínio da prática de clowning, cada vez mais relegada aos palcos de pouco prestígio dos teatros Fortune e Red Bull já mencionados. A transição para esse teatro avesso a clowns se torna evidente na análise do prólogo de Henrique VIII (1613), peça escrita por Shakespeare em parceria com John Fletcher (1579-1625), em que o público é avisado que a peça não irá "mesclar verdade com o tipo de intriga de bobo" (Pro.1.18-9).

A explicação dada aos gentle hearers da peça histórica indica que os dramaturgos, provavelmente Fletcher, em especial, buscavam dar contornos mais 
sérios e neoclássicos à arte produzida pela companhia, conhecida como King's Men desde a ascensão de Jaime I ao trono, em 1603. O sucessor de Armin, o clown John Shank (-1636), chegou a registrar uma petição ${ }^{14}$ em agosto de 1635 - um documento em que o ator se queixa de ser barrado de subir ao palco e cobra da companhia valores não quitados (HORNBACK, 2009, p. 185). Não há evidências concretas sobre o porquê de Shank ter sido afastado do palco. No entanto, a petição do ator pode ser um indício de que os tempos, de fato, eram outros e que os ventos do teatro não sopravam mais a favor dos clowns (HORNBACK, 2009, p. 185).

Chegava ao fim o período em que os atores cômicos eram donos de fama superior à do dramaturgo: a princípio, nem o próprio Shakespeare gozava do mesmo prestígio que Kemp. Foram necessários muitos anos para que ele conquistasse fama e reputação como as de seu ator cômico. Certamente, a celebridade dos clowns ajudou a instigar a curiosidade de Shakespeare pelas possibilidades de explorar o cômico em suas obras. Não por acaso, sempre houve espaço em suas peças - independentemente do gênero - para abrigar personagens cômicas, povoando o espaço dramático de suas obras com performances humorísticas de tirar o fôlego.

Nas palavras de Hornback (2009), dizer que são necessárias mais pesquisas sobre os atores cômicos de Shakespeare é dizer o óbvio. Mais do que trazer à tona informações sobre suas performances cômicas e seu inesgotável repertório humorístico, estudos sobre eles podem trazer revelações significativas sobre o cenário teatral, religioso, político, social e cultural da era elisabetano-jaimesca. Rir de clowns rústicos criados sob medida para Kemp, como Sly e Bobina, era rir da ingenuidade e da rudeza associadas ao estereótipo do inglês recém-chegado do interior - um numeroso grupo formado por pastores, alfaiates, tecelões, coveiros e porteiros que encontrava sua própria imagem estereotipada nas performances engraçadas dos rústicos shakespearianos. Sob essa perspectiva, investigar o papel dos clowns em Shakespeare é um trabalho arqueológico - significa se lançar à procura de significados hoje ocultos aos nossos olhos, buscando o que uma representação transmitia à luz de crenças, valores e conhecimentos que não são os nossos.

14 "A peticon of Iohn Shankes to my L Chamberlaine shewing that according to his Lo" order hee did make a proposition to his fellowes for satisfaccon vpon his assigening [sic] of his parts in ye seuerall houses vnto them bet they not onely refused to giue satisfaccon but restrained him from the Stage [...]. [Shanke is seeking] a proportionable \& equitable sume of money to bee payd vnto [him] for the two parts which he is to passe vnto Benfield, Swanston, \& Pollard \& to cause a finall agreemt \& convayances to bee settled accordingly." 


\section{" 0 worthy fool: motley is the only wear": the comic actors of the Shakespearean stage}

\section{Abstract}

At the beginning of Shakespeare's career, it was not his fame that attracted the crowds to the theatre, but his comic actors. This study aims to shed light on Shakespeare's comic actors' characteristics: Will Kemp and Robert Armin, analyzing some of the main aspects of their performances.

\section{Keywords}

Clown. Shakespeare. Comic actor.

\section{REFERÊNCIAS}

BELL, R. Shakespeare's great stage of fools. New York: Palgrave-Macmillan, 2011.

CAMPBELL, O. J. Shakespeare’s satire. New York: Gordian Press, 1971.

HARTLEY, A. J. Character, agency and the familiar actor. In: YACHNIN, P.; SLIGHTS, J. (ed.). Shakespeare and character: theory, history, performance and theatrical persons. New York: Palgrave Shakespeare Studies, 2009. p. 158-176.

HORNBACK, R. The English clown tradition from the Middle Ages to Shakespeare. Cambridge: D. S. Brewer, 2009.

OTTO, B. Fools are everywhere. Chicago: University of Chicago Press, 2001.

PREISS, R. Clowning and authorship in early modern theatre. Cambridge: Cambridge University Press, 2015.

VIDEBAEK, Be. The stage clown in Shakespeare's theatre. London: Greenwood Press, 1996.

WEIMANN, R.; BRUSTER, D. Shakespeare and the power of performance: stage and page in the Elizabethan theatre. Cambridge: Cambridge University Press, 2009.

WELSFORD, E. The fool. London: Faber and Faber, 1935.

WILES, D. Shakespeare's clown: actor and text in the Elizatbethan playhouse. Cambridge: Cambridge University Press, 1987. 